\title{
15 ANOS DA EDUCAÇÃO ESPECIAL NO MUNICÍPIO DE CAARAPÓ: CONSTRUINDO PRÁTICAS PEDAGÓGICAS INCLUSIVAS
}

\author{
15 AÑOS DE EDUCACIÓN ESPECIAL EN LA CIUDAD DE CAARAPÓ: \\ CONSTRUYENDO PRÁCTICAS PEDAGÓGICAS INCLUSIVAS
}

\author{
15 YEARS OF SPECIAL EDUCATION IN THE CITY OF CAARAPÓ: BUILDING \\ INCLUSIVE PEDAGOGICAL PRACTICES
}

\author{
Léa GELLER ${ }^{1}$ \\ Marli da Costa GONÇALVES ${ }^{2}$ \\ Luciene Barbosa VITOR LIMA ${ }^{3}$
}

RESUMO: O presente estudo busca retratar a história da construção da educação especial no município de Caarapó-MS, contemplando as mudanças ocorridas, contando um pouco da trajetória e as ações desenvolvidas pela Secretaria Municipal de Educação e Esportes (SMEDE) de Caarapó-MS, enfatizando as vivências, as experiências e as práticas desenvolvidas por meio do Atendimento Educacional Especializado (AEE), que ocorreram na linha de tempo de 2003 a 2018, concentrando-se no processo de evolução por que passou o AEE para transcender as vivências segregacionistas, integracionistas, partindo para a concepção da educação especial na perspectiva inclusiva. Desafios e perspectivas envolvendo o pensar e o fazer por meio das primeiras formações e atuações dos professores, chegando a um olhar integral do desenvolvimento humano, fomentando a autonomia e práticas educacionais que visem potenciar as habilidades dos estudantes.

PALAVRAS-CHAVE: Atendimento Educacional Especializado. Práticas pedagógicas. Inclusão.

RESUMEN: El presente estudio busca retratar la historia de la construcción de educación especial en la ciudad de Caarapó-MS, contemplando los cambios ocurridos, contando un poco de la trayectoria y las acciones desarrolladas por la Secretaría Municipal de Educación $y$ Deportes (SMEDE) de Caarapó-MS, haciendo hincapié en las experiencias, las experiencias y las prácticas desarrolladas a través de la Asistencia Educativa Especializada (AEE), que ocurrió en el cronograma de 2003 a 2018, centrándose en el proceso evolutivo que atravesó la AEE para trascender las experiencias segregacionistas e integracionistas, comenzando con la concepción de la educación especial en una perspectiva inclusiva. Desafíos y perspectivas que involucran pensar y hacer a través de la primera capacitación y

\footnotetext{
${ }^{1}$ Secretaria Municipal de Educação e Esportes de Caarapó (SMEEC), Caarapó - MS - Brasil. Psicóloga Escolar. Pós-graduada em Educação Especial pela Universidade Federal da Grande Dourados (UFGD/FAED). ORCID: https://orcid.org/0000-0001-5586-8331. E-mail: leageller@yahoo.com.br

${ }^{2}$ Secretaria Municipal de Educação e Esportes de Caarapó (SMEEC), Caarapó - MS - Brasil. Professora do Atendimento Educacional Especializado. ORCID: https://orcid.org/0000-0002-2651-833X. E-mail: marlycgoncalves@hotmail.com

${ }^{3}$ Secretaria Municipal de Educação e Esportes de Caarapó (SMEEC), Caarapó - MS - Brasil. Professora Alfabetizadora. Pós-graduada em Educação Especial pela Universidade Federal da Grande Dourados (UFGD/FAED). ORCID: https://orcid.org/0000-0002-0657-5118. E-mail: lucieneb.lima@ hotmail.com
} 
desempeño de los maestros, alcanzando una visión integral del desarrollo humano, fomentando la autonomía y las prácticas educativas destinadas a mejorar las habilidades de los estudiantes.

PALABRAS CLAVE: Servicio Educativo Especializado. Prácticas pedagógicas. Inclusión.

ABSTRACT: The present study seeks to portray the construction of special education history in Caarapó-MS, contemplating the changes performed, reporting a little about the trajectory and the actions developed by the Municipal Department of Education and Sports (MDES) of Caarapó-MS, emphasizing the livings, experiences and practices developed through the Specialized Educational Assistance (SEA), occurred between 2003 from 2018, focusing on the evolutionary process that passed the SEA to transcend the segregationist experiences, integrationists starting to conceptualize special education in an inclusive perspective. Challenges and perspectives involving thinking and doing through the first formations and actions of teachers, arriving at an holistic view of human development, fostering autonomy and educational practices aimed at enhancing students' abilities.

KEYWORDS: Specialized Educational Assistance. Pedagogical practices. Inclusion.

\section{Introdução}

A educação especial é um tema transversal que está em constante desenvolvimento, seguindo de acordo com os acontecimentos científicos, tecnológicos e ideológicos, possibilitando novas práticas pedagógicas que tornem cada vez mais possível a inclusão da pessoa com deficiência. No presente estudo, abordaremos como se construíram e se desenvolvem as práticas educacionais da educação especial no Município de Caarapó, de forma a agregar valores e possibilitar a visualização do Atendimento Educacional Especializado (AEE), que assiste os estudantes públicos-alvo da educação especial, potencializando as ações voltadas para a conquista da escola inclusiva como uma das metas a serem atingidas do Plano Municipal de Educação (PME).

Diante da meta e viabilização da escola inclusiva, os sujeitos beneficiados com essas conquistas são os estudantes, pois todo o trabalho desenvolvido e planejado é baseado na melhor forma de atender a todos os alunos, sem excluir nenhuma minoria, porém ressaltamos que no texto abordaremos especificamente a educação especial na perspectiva da educação inclusiva.

Seguindo a evolução ideológica, norteou-se a legislação brasileira, que trouxe em seus textos princípios fundamentais para a organização escolar, tornando a educação um direito de todos, em que todos têm direito a uma educação de qualidade, como veremos nos parágrafos seguintes. 
A Constituição Federal de 1988 estabelece alguns princípios para a educação:

\begin{abstract}
Art. $3 .^{\circ}$, IV - promover o bem de todos, sem preconceitos de origem, raça, sexo, cor, idade e quaisquer outras formas de discriminação. Art. 205. A educação, direito de todos e dever do Estado e da família, será promovida e incentivada com a colaboração da sociedade, visando ao pleno desenvolvimento da pessoa, seu preparo para o exercício da cidadania e sua qualificação para o trabalho. Art. 206, I - igualdade de condições para o acesso e permanência na escola. Art. 208. É dever do Estado a oferta do atendimento educacional especializado, preferencialmente na rede regular de ensino.
\end{abstract}

A construção e elaboração de políticas públicas internacionais e nacionais, na busca por uma educação inclusiva, ocorreram em prol de um movimento social e individual para que todos pudessem ter acesso e participação na sociedade. No Brasil, iniciou-se por meio da Declaração Mundial de Educação para Todos (1990) e da Declaração de Salamanca (1994), que dispõe sobre os princípios, políticas e práticas na área das necessidades educacionais específicas. Esta última define as crianças com necessidades específicas, como aquelas:

[...] crianças com deficiência e crianças bem-dotadas; crianças que vivem nas ruas e que trabalham; crianças de populações distantes ou nômades; crianças de minorias linguísticas, étnicas ou culturais e crianças de outros grupos ou zonas desfavorecidos ou marginalizados (SALAMANCA, 1994, p. 17).

Em 1999, foi realizada a Convenção da Guatemala (1999) da qual o Brasil é signatário, por meio do Decreto 3.956/2001, que regulamenta que as pessoas com deficiência têm os mesmos direitos humanos e liberdades fundamentais que as demais pessoas, definindo como discriminação com base na deficiência toda diferenciação ou exclusão que possa impedir ou anular o exercício dos direitos humanos e de suas liberdades fundamentais.

Em defesa da superação da discriminação e exclusão, há a necessidade de fortalecer as diretrizes educacionais, e, nesse sentido, é criada a Política Nacional da Educação Especial na Perspectiva da Educação Inclusiva (2008), deixando evidente que a inclusão é uma ação política, cultural, social e pedagógica, pautada por mudanças atitudinais e superação de paradigmas. Tais esforços foram feitos em conjunto com o objetivo de alcançar uma sociedade em que a pessoa com e sem deficiência, a família, a escola, os professores, a legislação, entre outros, possam colaborar e romper as barreiras, garantindo o direito à participação e a interação entre os envolvidos, sendo mais justa e equânime. 
A Política Nacional de Educação Especial na Perspectiva da Educação Inclusiva (2008) foi elaborada segundo os preceitos de uma escola em que cada aluno tem a possibilidade de aprender, a partir de suas aptidões e capacidades, e em que o conhecimento se constrói sem resistência ou submissão ao que é selecionado para compor o currículo, resultando na promoção de alguns alunos e na marginalização de outros do processo escolar. A compreensão da educação especial nesta perspectiva está relacionada a uma concepção e a práticas da escola comum que mudam a lógica do processo de escolarização, a sua organização e o estatuto dos saberes que são objeto do ensino formal. Como modalidade que não substitui a escolarização de alunos com deficiência, com transtornos globais de desenvolvimento e com altas habilidades/superdotação, essa educação supõe uma escola que não exclui alunos que não atendam ao perfil idealizado institucionalmente (CAVALCANTE, 2011, p. 1).

Nesse sentido, o município de Caarapó iniciou as primeiras discussões e formações voltadas para o público da educação especial em 2003, pensando-se um trabalho em específico com os surdos, ocorrendo a divulgação da Libras, tudo muito superficial, diálogos iniciais sobre a deficiência intelectual, segundo documentação encontrada na secretaria e relatos orais. Por isso, faz-se necessário destacar a importância de reconhecer a prática de investigação social, que se apresenta extremamente significante com o uso da história oral.

Portelli (2010) analisa como a relação entre história e memória, a busca de fragmentos com o intuito de descrever modos culturais, por meio de história oral com o viés de analisar contextos sociais para compreender problemáticas do contexto envolvido, das memórias, culturas e identidades.

Assim, o texto apresenta uma abordagem qualitativa, de forma descritiva, uma metodologia de pesquisa de campo nos moldes da história oral, que retratará acontecimentos em um determinado tempo e contexto a partir de vivências, documentos, relatos orais e literatura envolvendo a temática. Da escola que temos ao que queremos, é uma indagação, pode-se dizer, que o texto nos faz. A inclusão é algo real, conquistas atitudinais e legalmente alcançadas por pessoas que acreditam no respeito e na valorização das diferenças, numa educação de e para todos. Contudo, ao observarmos nossa realidade escolar, podemos constatar que ainda há muito a se fazer, além de incluir pessoas com deficiência no âmbito educacional.

\section{Desenvolvimento}

Com a implementação da nova política, o município foi se organizando, e as primeiras experiências não foram fáceis e deixaram marcas na vida de alunos e famílias. A educação infantil recebeu o primeiro aluno com síndrome de Down e não se sabia o que fazer, como 
agir. O estudante ia para a escola e não permanecia na sala de aula, passeava o tempo todo pelo pátio, ficava no parquinho, mas não havia uma preocupação de aprendizado acadêmico, nem por parte dos professores tampouco da família. Faltavam formação, informação, vencer os mitos, dissociando a síndrome do comprometimento cognitivo. Claramente, o estudante estava integrado no processo, mas não havia participação e desenvolvimento e, aos poucos, a família foi desistindo da escola comum e optando pela escola especial, na qual o estudante se encontra até os dias de hoje.

O novo gera receio e ansiedade, e nesse sentido não foi diferente para a rede municipal e seus professores, que estavam todos apavorados. As expectativas da família com relação à escola que estava sendo "obrigada" a atender as crianças com deficiência, um serviço que estava se estruturando e surgindo em prol do público e o desespero dos professores que só pensavam nas habilidades acadêmicas que os estudantes deveriam alcançar.

Por isso, a necessidade de formação era urgente e emergente, tendo a cidade de Dourados como referência e parceria na busca por caminhos a seguir. Nóvoa (2004) afirma que não devem faltar à formação docente três princípios: a pessoa, a partilha e a prudência. Essa tríade dialoga fluidamente com o princípio da inclusão. O trabalho foi se construindo com o intuito de atender as escolas municipais e os centros de educação infantil. As práticas dos professores especialistas no AEE eram variadas no contexto escolar: orientação ao professor para diminuir suas angústias, orientação ao coordenador pedagógico apontando quais atividades poderiam ser desenvolvidas com os estudantes com deficiência. No entanto, vale ressaltar que não foi um caminho fácil, principalmente quando a ideologia da época centrava-se no aprendizado acadêmico como primordial, considerando o ler e escrever como regra de alfabetização. Diante das necessidades existentes, implantou-se a primeira sala de recurso multifuncional na escola Cândido Lemes dos Santos, no ano de 2006, como mostra a foto à esquerda, e as primeiras alunas atendidas pela educação municipal eram surdas, tendo a atuação de uma professora especialista que passou pelo processo de formações específicas oferecidas até em então, pautadas e norteadas pelas políticas do Ministério da Educação e Cultura (MEC, 2001). 
Figura 1 - Atendimento ofertado a estudantes surdas em 25.09.2006

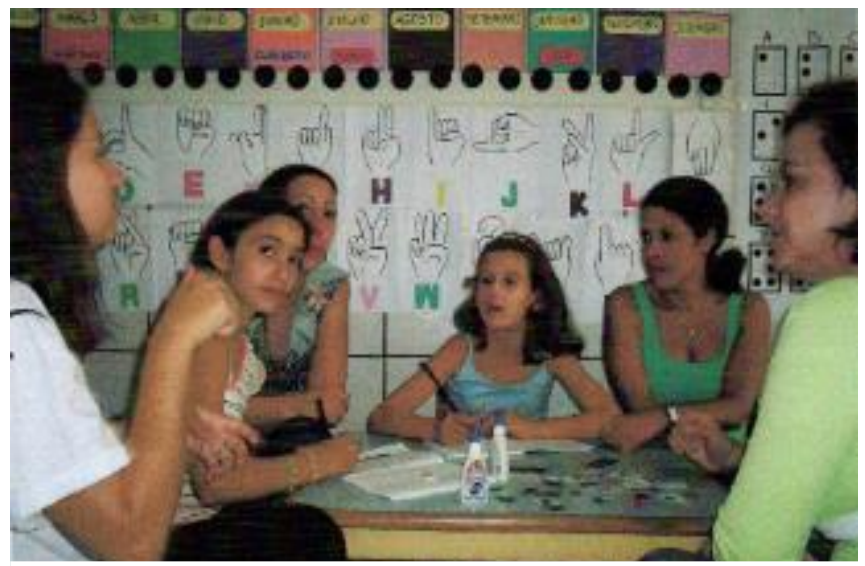

Fonte: Acervo próprio

Em 2010, são abertas a segunda e a terceira salas de recurso multifuncional, respectivamente na Escola Rui Barbosa e na Escola Professor Moacir Franco de Carvalho, com a atuação de professores especialistas. Na primeira, priorizou-se o atendimento a estudantes com laudo, sendo todos com deficiência intelectual inicialmente; na segunda escola, o público era mais diverso, atendendo crianças com deficiência visual (cegueira), deficiência múltipla e intelectual. No primeiro semestre de 2010, analisou-se como seriam os atendimentos, qual seria o público-alvo, as leis que norteariam o atendimento, foram confeccionados materiais e um plano anual de atendimento.

No ano de 2012, começaram a implantação e a implementação do AEE na escola indígena e, para tanto, foram realizadas a formação e a preparação de um professor indígena, uma vez que não havia um profissional preparado para essa modalidade de ensino. A Secretaria de Educação oferece cursos e formação continuada aos professores que trabalham nesse contexto. A escola indígena atualmente possui em torno de 1.500 alunos atendidos na escola polo e três extensões. A professora que atende o AEE desenvolve seu trabalho de maneira itinerante para acompanhar os processos de produção do planejamento inclusivo, e os estudantes são transportados até a escola onde fica localizada a sala de recursos para receber o atendimento individualizado ou em pequenos grupos.

É importante ressaltar que a cultura Guarani Kaiowá é bem presente, inclusive a língua materna Guarani é a mais falada, garantindo-se, assim, a alfabetização na língua materna. E não poderia ser diferente no AEE, sendo imprescindível um profissional indígena falante do 
Guarani para atender os alunos e buscar a eliminação de barreiras existentes na comunidade indígena para o atendimento do estudante público-alvo da educação especial.

Ainda há muito a melhorar e barreiras a serem eliminadas, pois a cultura Guarani Kaiowá ou a compreensão de que todos têm direito à educação nessa região do nosso município ainda é um desafio, que aos poucos vem sendo vencido, pois os estudantes indígenas com deficiência estão cada vez mais presentes em sala de aula. Ainda não podemos dizer que estão incluídos, porém, com certeza, estão integrados e sendo vistos, numa sociedade em que até pouco tempo atrás eram invisíveis.

A implantação do espaço ocorreu em 2013, e, diante da falta de professores indígenas habilitados em educação especial, notamos que a metodologia de ensino aplicada no AEE deve ser revista e que, em alguns momentos, é aplicada nos moldes do apoio escolar. Essa metodologia adotada está em constante discussão nos estudos realizados na Secretaria Municipal de Educação.

Em 2016, iniciou-se a estruturação do espaço para equipar uma sala de recurso multifuncional na Educação Infantil, além da preparação da professora especialista por meio de formações e acompanhamento do trabalho dos professores que já atuavam no AEE, visando aprimorar o atendimento a esse público, que até então era realizado no AEE apenas quando o estudante chegava ao ensino fundamental. Criaram-se, assim, grandes expectativas com relação à melhoria do trabalho de estimulação inicial. Em 2017, a professora iniciou o atendimento às crianças da educação infantil, com o espaço centralizado em um Centro Municipal de Educação Infantil (CMEI), de forma itinerante, para atender a todos os CMEIs, inclusive às crianças de creche (0 a 3 anos), com orientação aos professores e o atendimento individualizado no AEE a partir dos 4 anos de idade.

Apresentadas todas as dificuldades e complexidades do serviço, mas aos poucos ocorrendo alguns avanços, o relevante é que esse público estava procurando escola, e nela permanecia, e os esforços direcionados para que, além do acesso, houvesse participação e aprendizado.

Podemos destacar que as atividades, por um período, principalmente antes da compreensão da política norteadora de 2008 e da conscientização de que o trabalho não foi construído do dia para noite, eram realizadas individualmente, com trocas de informações com professores pelos corredores, com o anseio de que os estudantes se apropriassem rapidamente do conhecimento acadêmico. No entanto, isso não ocorreu, pois, mesmo com a individualidade, eles necessitavam de um tempo maior para aprender e desenvolver conceitos. A grande dificuldade encontrada não foi com relação aos estudantes, e sim à grande 
expectativa de seus professores que acreditavam que, se enviassem os estudantes ao AEE, o problema estaria resolvido.

Ao longo do processo, tudo isso atrasou muito o caminhar e a efetivação do serviço dentro da escola. Semanalmente, na reunião que acontece na Secretaria Municipal de Educação e Esportes (SMEDE), ocorrem as trocas de ideias e experiências, momento em que há defesas de pontos de vista, quando, juntos, buscam chegar a um consenso de como agir em cada situação, além de estudos e formações para colaborarem na prática de ensino do AEE.

Nesses anos, houve muitas mudanças, novas perspectivas, o integrar passou a ser questionado e a preocupação em incluir era cada vez mais gritante. A resistência ainda é grande, há muitas arestas a serem aparadas, muito a se pensar e fazer, o serviço a ser compreendido e realizado a favor do aluno, da escola, promovendo a inclusão, e não um atendimento segregado, como ocorreu por muito tempo.

O professor do AEE, por algum tempo no município, realizou um atendimento muito voltado para as necessidades da sala de aula (reforçando os conteúdos trabalhados na sala), e aos poucos, percebendo que não é o estudante que deve se adaptar à escola, mas a escola que deve, com as necessidades do aluno, realizar um movimento a favor, com ações, buscando atender suas especificidades, o que, paulatinamente, com as formações oferecidas e também com a busca desse profissional por caminhos mais assertivos, essa concepção foi mudando, novos caminhos e metodologias foram pensados e organizados.

Nesse sentido, uma formação oferecida, em 2016, pela Universidade Federal da Grande Dourados, um curso de extensão coordenado pela professora Doutora Mirlene Ferreira Macedo Damázio, “Atendimento Educacional Especializado: seu pensar, sentir e fazer", provocou mudanças de paradigmas e fortaleceu as modificações atitudinais e conceituais perante o atendimento aos alunos com deficiência na rede municipal.

Assim, as competências políticas, legais e pedagógicas foram se fortalecendo, mudando a forma de ver e pensar o AEE, até para os próprios especialistas atuantes, levando a todos os que fazem parte do movimento e que são amparados pela gestão da educação especial e da SMEDE a sair da política integracionista, assumir de fato uma educação inclusiva e trabalhar nos moldes da Política Nacional de Educação Especial na Perspectiva da Educação Inclusiva (BRASIL, 2008). Sobre o assunto, Mantoan (2003, p. 56) destaca que "a inclusão não é simplesmente inserir a pessoa na escola e nos ambientes destinados a sua educação, saúde, lazer, trabalho".

Incluir implica acolher a todos os membros de um grupo, atender suas necessidades, levando em consideração suas especificidades, promovendo e rompendo as barreiras, não 
apenas pautar nas habilidades acadêmicas de forma convencional, mas criar caminhos para alcançá-las, visando o princípio da equidade e da valorização das diferenças. Conforme Almeida e Geller (2018, p. 857), “incluir é humanizar - é aprender a viver juntos! -, e que o sentido da escola é produzir as condições necessárias para que esta humanização aconteça".

Buscando atender esses conceitos, em 2017, todos os profissionais envolvidos com a educação especial - psicólogos, professores do AEE, técnicos da SMEDE - se colocaram à disposição e foram em busca de aprender e fortalecer sua prática na educação especial. Nesse contexto, houve uma parceria da SMEDE e da UFGD/FAED, em que a equipe de educação especial do município recebeu uma assessoria técnica da professora Doutora Mirlene Ferreira Macedo Damázio sobre o Plano de Desenvolvimento Individualizado e as ações necessárias para realizar um trabalho em prol da inclusão, o que possibilitou avanços conceituais e mudanças de postura em face do acompanhamento do aluno com deficiência em específico, mas sem deixar de pensar nos outros estudantes com necessidades educacionais específicas.

\section{Construindo caminhos: práticas iniciais no AEE}

O AEE iniciou sua trajetória no município de Caarapó-MS, como em muitos outros do País, visto como aquele que faria o que não era "possível" ou não realizado em sala de aula comum, por exemplo, sair da integração e partir para ações efetivas de inclusão, participação, acesso ao conteúdo, flexibilização, ou seja, atender as especificidades desse público (MANTOAN, 2003).

Nesse panorama, podemos destacar que sua efetivação se deu a curtos passos, avanços e retrocessos. Para começar, deparamo-nos com as barreiras financeiras e materiais; foi disponibilizado espaço, mas não havia materiais próprios e adequados, e as escolas foram se organizando e improvisando. Paralelamente, ocorria a formação e o assunto era divulgado, com a necessidade de efetivar o serviço para atender a legislação.

Em 2005, ocorreu uma formação intitulada "A Secretaria Municipal de Educação Cultura e Esportes (SMECE) Fazendo Inclusão", com a professora Mariuza Aparecida Camilo Guimarães, oferecida a todos os professores da rede, trazendo conceitos pertinentes até hoje, como a valorização das diferenças, terminologias, legislação, escola para todos, a importância da avaliação, como realizar um trabalho em sala de aula comum e no próprio AEE. Entretanto, diante do novo, do que não é tão urgente, o interesse a importância ao assunto não se fez tão relevante, destaca se ainda que, na época, havia poucos estudantes como público-alvo, o que não provocou maior interesse e participação por parte dos 
professores, assinalando que não houve sentimento de pertença pelo o que estava sendo oferecido, pois naquele momento havia uma possibilidade de mudança de paradigmas.

Figura 2 - Assessoria a classe comum, ano 2017

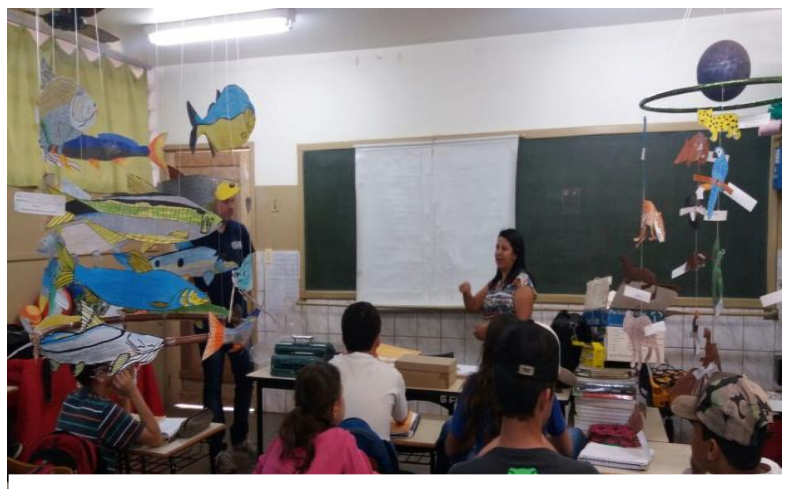

Fonte: Acervo próprio

O AEE, inicialmente, era visto apenas pelo atendimento realizado na sala de recurso multifuncional, professor especialista e estudante, ocorrendo a falta de comprometimento e de pertença por parte de alguns professores da sala de aula comum, acreditando erroneamente que o AEE faria o trabalho da sala de aula comum, trabalhando os conteúdos e realizando a tão desejada alfabetização.

As práticas pedagógicas foram sendo construídas com o olhar de apoio e suporte a esse público, trabalhando inicialmente o "eu”, pois a autoestima dos alunos com deficiência é fragilizada e prejudicada, os estudantes não se veem como alguém capaz de realizar ou aprender, por isso a importância de trabalhar a autoestima, com reforço positivo dos pequenos avanços e conquistas. Essa foi uma grande preocupação desde o início do trabalho do AEE. Com relação às práticas de ensino, a construção identitária de como e o que fazer foi e está em andamento, pois por muito tempo a responsabilização do desenvolvimento acadêmico desse estudante foi vista e pensada como função do AEE. No entanto, esse cenário vem sendo mudado com as intervenções e orientações dadas via secretaria (SMEDE) aos coordenadores, professores e gestão escolar e pelo comprometimento da escola com os alunos público-alvo da educação especial.

As práticas educacionais no atendimento educacional especializado pautou-se por uma metodologia que visa atender as necessidades dos estudantes a partir de um suporte a vencer seus desafios e avançar na classe comum, com atendimento individualizado ou em pequenos 
grupos (2 ou 3 estudantes com as necessidades semelhantes), apostando no uso de jogos e o lúdico como ferramenta no processo de ensino desses alunos, realizando uma avaliação a partir das funções mentais superiores, baseada nos diferentes estilos de aprendizagem e inteligência emocional (GARDNER, 2010; GOLEMAN, 1995).

Em 2018, avanços foram conquistados, o sentimento de pertença por parte de professores especialistas e principalmente da escola e dos professores de sala de aula comum pode ser destacado como ponto de partida para as práticas inclusivas. A sala de recurso multifuncional deixa de ter tanto "valor" e é reconhecida como um dos espaços para o atendimento educacional especializado, principalmente por ela não ser um lugar que privilegia apenas um professor que atende "poucos alunos", enquanto a sala de aula comum está saturada com os problemas mais diversos, mas é um espaço que pertence à escola e que deve colaborar com o trabalho de todos e para todos, no intuito de atender e realizar um serviço de parceria e um trabalho colaborativo, que se efetiva nos diversos espaços escolares: na sala de aula comum, na quadra de esportes na aula de educação física, adequando material, ouvindo o professor de sala de aula comum e juntos construindo possibilidades para a inclusão do aluno.

Figura 3 - Participação dos estudantes em projeto de leitura extraclasse

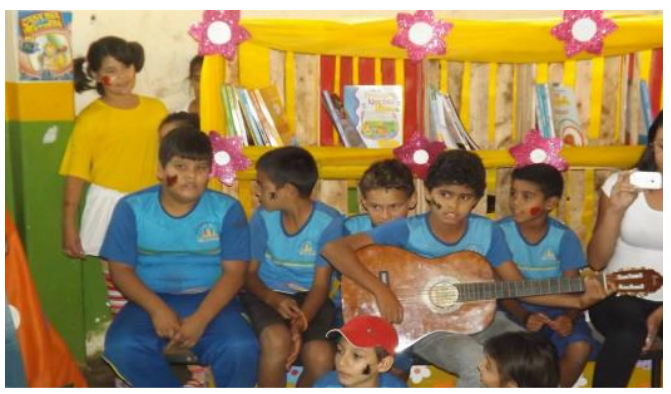

Fonte: Acervo próprio

Para os profissionais da educação, é evidente que, no tocante à inclusão, não há receita pronta, mas há que se colocar à disposição para fazer, estar aberto a aprender, fazer, refazer, construir e questionar acima de tudo. "Afinal, inclusão é isso: Mudar o mundo continuamente, em direção à formação de uma juventude mais aberta, não conservadora, valores éticos vinculados aos humanos, incluindo o direito de ser, participar e usufruir" (SANTOS, 2018, p 28). 


\section{Construindo caminhos: práticas ideais no AEE}

A partir da afirmação de Santos (2018), inclusão é um processo contínuo, e assim nunca terá fim, sua implantação depende especificamente da atitude de cada um, do sentimento de pertença que os professores e toda a equipe escolar tenha pelo processo de formação integral de todos os estudantes, sem distinção. Quando pensamos na escola, a prática do professor entra em questão, pois é a partir de sua ação que as práticas pedagógicas poderão se efetivar a favor do estudante e do seu desenvolvimento integral dentro da escola comum.

Figura 4 - Atividade sequenciada realizada em sala de aula comum, a importância do concreto e significado

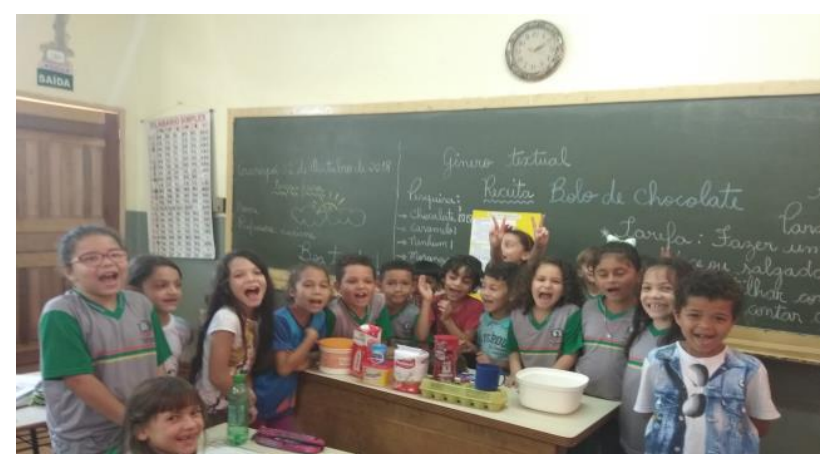

Fonte: Acervo Próprio

Como mencionado, há algumas interpretações equivocadas com relação ao AEE, que se trata de um serviço oferecido pela educação especial, que se configura como uma modalidade de ensino que perpassa todos os níveis e modalidades da educação, desde a Educação Infantil até o Ensino Superior. A sala de recurso multifuncional é apenas um espaço que colabora com o trabalho do professor do AEE e com uma das necessidades do estudante público-alvo da educação especial, que é o atendimento individualizado, mas esse serviço vai além do suporte individual, ele está na escola para colaborar e articular ações para promover a inclusão.

Dámazio (2018, p. 48) traz em detalhes alguns serviços desenvolvidos pelo professor do AEE de acordo com o perfil do estudante:

1. Acolhimento inicial deelaboração do plano de AEE de acordo com o perfil do estudante; 
2. Atendimento individual ao estudante ou em subgrupos na SRM; 3. Adequação de material pedagógico e tecnologia assistiva (TA);

4. Apoio e assessoria ao estudante na sala de aula comum de ensino regular;

5.Apoio assessoria ao professor de classe comum;

6.Apoio e assessoria ao professor de arte e educação física;

7.Apoio e assessoria ao professor de apoio escolar;

8.Apoio e assessoria aos monitores, cuidadores e/ou estagiário;

9.Apoio e assessoria aos gestores (direção e coordenação);

10.Apoio e orientação à família;

11. Ações intersetoriais - saúde, ação social etc.

12. Elaboração de pareceres e relatórios descritivos analíticos de cunho pedagógico.

Assim, podemos compreender as especificidades do serviço e perceber que o professor do AEE pode colaborar de forma significativa com o contexto educacioanal, mas é a ação pedagógica e metodológica de todos da escola que fará a diferença na vida dos estudantes, em especial do público-alvo da educação especial, que são os estudantes com deficiência, transtornos globais do desenvolvimento, altas habilidades e superdotação, que no percurso educacional necessitarão de complemento e/ou suplemento.

Para Stainback e Stainback (1999), o educador é visto como articulador de um importante papel na percepção de que os alunos têm potencialidades e necessidades diferentes. E é pela mediação, conforme destaca Vygotsky (1989), que o ser humano pode, desde cedo, atribuir sentido e significado às coisas.

Estamos passando por um momento de transformações, em um cenário educacional diverso com diferentes necessidades, sendo fundamentais a gestão escolar consciente do seu contexto e tudo que o cerca, o acompanhamento pedagógico, bem como um trabalho colaborativo e em parceria. 
Figura 5 - Formação em serviço: Participação em evento - VI OIIIPe/2018, confirmando e refutando práticas do AEE

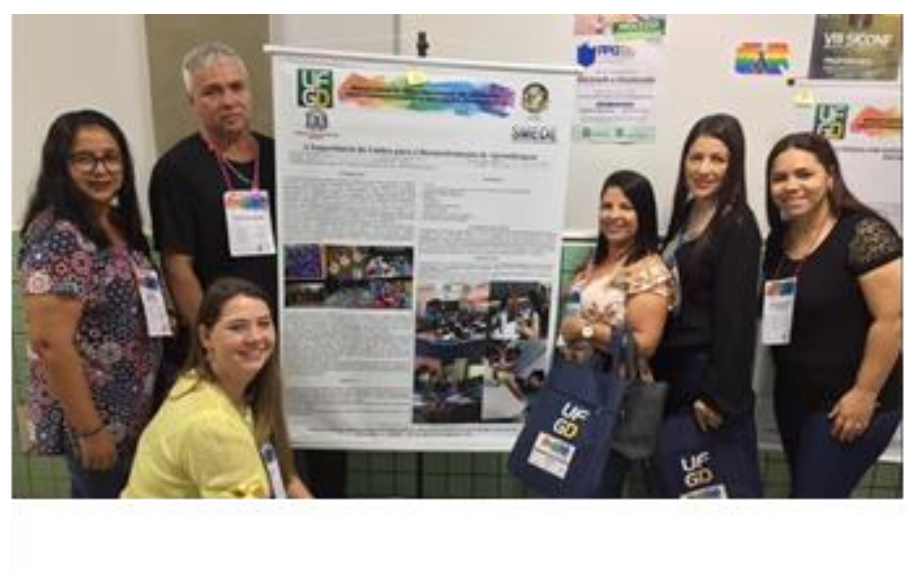

Fonte: Acervo Próprio

Figura 6 - Atividade realizada em sala de aula comum, intervenção e supervisão do AEE.

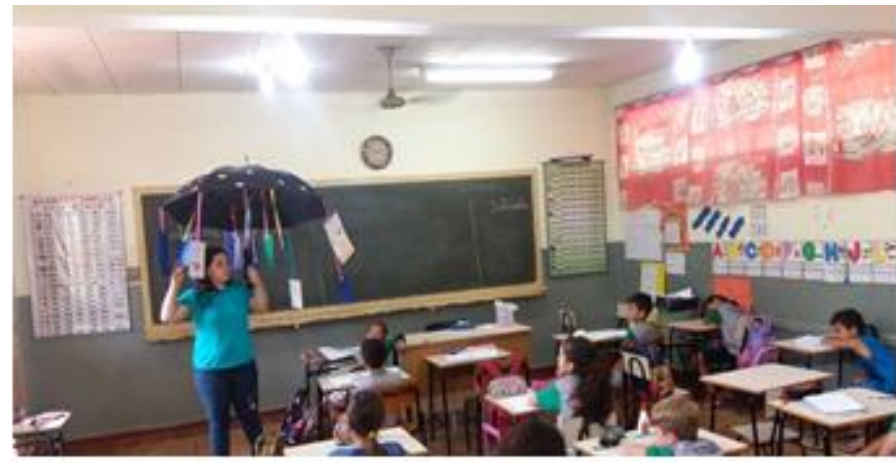

Fonte: Acervo Próprio

Por isso, a importância de destacar a formação dos professores, a ação de ser pesquisador nesse processo educacional, acompanhado de mudanças extremas e necessárias, no qual todo o aparato legal não se faz suficiente para que possamos ver assegurado e garantido o direito de muitos indivíduos, com deficiência ou não.

$\mathrm{Na}$ escola, sabemos que as diferenças são mais evidentes, sejam elas sociais ou econômicas. Nesse sentido, podemos evidenciar o papel do professor e sua mediação nessas essas realidades complexas e desafiadoras, em que ele precisa estar disposto, a todo momento, 
a aprender, inovar, questionar e até inventar soluções e estratégias para lidar com a sociedade em constantes mudanças e infinitas certezas.

Portanto, acreditamos na parceria, no trabalho em conjunto, que todos na escola possam falar a mesma língua, pois assim bons resultados virão. Perrenoud (2005), dizia que uma prática inovadora e eficaz não se decreta. Ela se desenvolve com uma rede de apoio, participação nas discussões e decisões, todos assumindo regras e compartilhando responsabilidades para que se alcance o produto final.

Bonfrenbrenner (1996) faz-nos refletir sobre a importância do outro, que ninguém é alguém sozinho, e é na complementaridade que se chegará a algum lugar. Na junção, poderse-á alcançar bons resultados, principalmente no trabalho escolar e pedagógico. E no trabalho na educação especial no AEE, em específico, esse conceito deve estar muito presente; o professor especialista é responsável por mediar e articular com a escola todo esse processo de inclusão dos estudantes em parceria com o professor da sala de aula comum, podendo assim ter a possibilidade de formação em serviço, trocas de experiências e conhecimento. Mantoan e Pietro (2006) falam das mudanças atitudinais, posturais de dentro para fora, da necessidade de sair da zona de conforto, e é necessário tanto o professor da classe comum quanto o professor especialista estarem na escola articulando e apoiando o processo dessas mudanças no atendimento às diferenças dos estudantes, oferecendo-lhes condições de prosseguir em seus estudos, segundo a capacidade de cada um, sem discriminação nem espaços segregados da educação.

\section{Conclusão}

Pensando no processo de implantação da Política Nacional na Perspectiva da Educação Inclusiva, no Brasil, em especial no município de Caarapó-MS, podemos dizer que são recentes as discussões, mas não são prematuras, e os profissionais precisam estar cientes do seu compromisso com a educação, necessitando traçar caminhos alternativos, assertivos ou não. Reconhecemos que não pode ocorrer a estagnação do serviço, ou ficar pautado por um velho modelo de escola, norteado pelos conceitos de normalidade, e pelos alunos que conseguem aprender nos moldes convencionais, mas cientes de que, para se ter uma educação de qualidade, é preciso buscar práticas significativas e reunir forças para que todos sejam atendidos em suas necessidades e especificidades, percebendo o leque de possibilidades de atuação acadêmica que cada aluno nos evidencia em seu cotidiano escolar. 
Nesse sentido, o serviço do AEE estará colaborando por meio de ações, mudanças conceituais e de paradigmas que visam esclarecer que, de fato, todos são capazes, tanto os educadores e detentores das suas ações de práxis pedagógica, com práticas humanizadas e empáticas compartilhando dores, dúvidas e anseios, com serenidade, respeito e afeto, quanto nossos estudantes, em especial o público-alvo do AEE, que, ao chegarem à escola ou serem diagnosticados com uma deficiência, são estigmatizados e tachados, com sentimentos de descrenças, o que não é real, e muito menos deve continuar ocorrendo na escola.

No município de Caarapó, todo o serviço passou por uma estruturação, desde a aquisição de materiais e equipamentos, de acessibilidade estrutural, reformas prediais, formação de professores, mas principalmente existiu o desejo de sensibilizar e conscientizar a rede municipal de ensino, em toda a sua amplitude, da importância do serviço da educação especial, por meio da aceitação e valorização das diferenças para promoção de uma educação inclusiva, que ainda está sendo construída. No entanto, mesmo com a certeza de que muitas conquistas já foram alcançadas e que, com amor, trabalho, dedicação e o olhar sensível, as mudanças ocorreram e compreendeu-se o alunado como ser humano em desenvolvimento, ainda temos muito a conquistar. Assim, concluímos este artigo com o sentimento de anseio por dias melhores para a educação especial.

\section{REFERÊNCIAS}

ALMEIDA, D. M. de M.; GELLER, L. Psicologia e educação: transdisciplinaridade na construção do atendimento educacional especializado de Caarapó-MS. RPGE - Revista online de Política e Gestão Educacional, Araraquara, v. 22, n. esp. 2, p. 856-871, 2018. Disponível em: https://periodicos.fclar.unesp.br/rpge/issue/view/709. Acesso em: 18 de dez. 2018.

BRASIL. Constituição Federal, de 5 de outubro de 1988. Brasília: Imprensa Oficial, 1988.

BRASIL. Lei n. 9.394/96, de 20 de dezembro de 1996. Brasília: MEC, 1996.

BRASIL. Política Nacional de Educação Especial na Perspectiva da Educação Inclusiva. Brasília: MEC/Seespe, 2008.

BRASIL. Decreto n. 7.611, de 17 de novembro de 2011. Dispõe sobre a educação especial, o atendimento especializado. Disponível em: http://www.planalto.gov.br/ccivil_03/_Ato20112014/2011/Decreto/D7611.htm. Acessado em: 10 dez. 2018.

BRASIL. Lei n. 13. 146, de 6 julho de 2015. Lei Brasileira de Inclusão. Disponível em: http://www.planalto.gov.br/CCIVIL_03/_Ato2015-2018/2015/Lei/L13146.htm. Acesso em: 10 dez. 2018. 
BRONFENBRENNER, U. A ecologia do desenvolvimento humano: experimentos naturais e planejados. Porto Alegre: Artes Médicas, 1996.

CAVALCANTE, M. Crescimento da política de inclusão é realidade no país. 2011.

Disponível em: https://inclusaoja.com.br/author/mecavalcante/page/15/. Acesso em: 12 dez. 2018.

DAMÁZIO, M. F. M. Atendimento educacional especializado em uma perspectiva inclusiva: metodologia em questão. In: FRANCO, M. A. M.; GUERRA, L. B. Práticas pedagógicas em contextos de inclusão: situações de sala de aula. Jundiaí: Paco, 2018. v. 3.

DECLARAÇÃo DE SALAMANCA: Sobre Princípios, Políticas e Práticas na Área das Necessidades Educativas Especiais, 1994, Salamanca-Espanha.

GARDNER, H. Inteligências múltiplas: ao redor do mundo. Rio de Janeiro: Artimed, 2010.

GOLEMAN, D. Inteligência emocional. Rio de Janeiro: Objetiva, 1995.

MENDES, E. G. A radicalização do debate sobre inclusão escolar no Brasil. Revista Brasileira de Educação, v. 11, n. 33, set./dez. 2006.

MANTOAN, M. T. E. Inclusão escolar: o que é? por quê? como fazer?. São Paulo: Moderna, 2003.

MANTOAN, M. T. E; PIETRO, R. G. Inclusão Escolar: Pontos e contrapontos. São Paulo: Sumus, 2006.

NÓVOA, A. Currículo e docência: a pessoa, a partilha, a prudência. In: GONSALVES, E.; PEREIRA, M. Z.; CARVALHO, M. E. (Org.). Currículo e contemporaneidade: questões emergentes. Campinas: Alínea, 2004. p. 17-29.

PERRENEUD, P. et al. A Escola de A a Z: 26 maneiras de repensar a educação. Porto Alegre: Artmed, 2005.

PORTELLI, A. Ensaios de história oral. São Paulo: Letra e Voz, 2010.

SANTOS, M. P. dos. $38+2 \neq 40$. In: FRANCO, M. A. M.; GUERRA, L. B. Práticas pedagógicas em contextos de inclusão: situações de sala de aula. Jundiaí: Paco, 2018, v. 3.

STAINBACK, S.; STAINBACK, W. Inclusão: um guia para educadores. Tradução Magda França Lopes. Porto Alegre: Artes Médicas, 1999.

VYGOTSKY, L. S. A formação social da mente: o desenvolvimento dos processos psicológicos superiores. 3. ed. São Paulo: Martins Fontes, 1989. 168p. (Coleção Psicologia e Pedagogia. Nova Série). 


\section{Como referenciar este artigo}

GELLER, Léa, GONÇALVES, Marli da Costa e LIMA, Luciene Barbosa Vitor. 15 anos da educação especial no município de Caarapó: construindo práticas pedagógicas inclusivas. Doxa: Rev. Bras. Psico. e Educ., Araraquara, v. 21, n. 2, p. 208-225, jul./dez. 2019. e-ISSN: 2594-8385. DOI: https://doi.org/10.30715/doxa.v21i2.13089

Submetido em: 20/02/2019

Aprovado em: 20/07/2019

Publicado em: 01/08/2019 